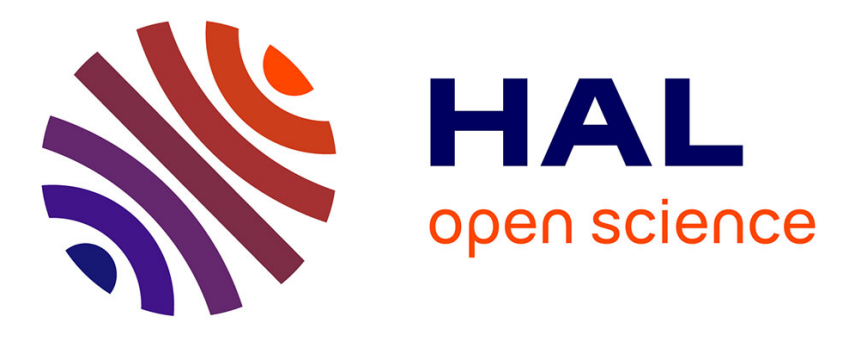

\title{
Terahertz-bandwidth coherence measurements of a quantum dash laser in passive and active mode-locking operation
}

\author{
Eamonn Martin, Regan Watts, Laurent Bramerie, Alexandre Shen, Harry \\ Gariah, Fabrice Blache, François Lelarge, Liam P. Barry
}

\section{To cite this version:}

Eamonn Martin, Regan Watts, Laurent Bramerie, Alexandre Shen, Harry Gariah, et al.. Terahertzbandwidth coherence measurements of a quantum dash laser in passive and active mode-locking operation. Optics Letters, 2012, 37 (23), pp.4967-4969. 10.1364/OL.37.004967 . hal-00824414

\section{HAL Id: hal-00824414 https://hal.science/hal-00824414}

Submitted on 21 May 2013

HAL is a multi-disciplinary open access archive for the deposit and dissemination of scientific research documents, whether they are published or not. The documents may come from teaching and research institutions in France or abroad, or from public or private research centers.
L'archive ouverte pluridisciplinaire HAL, est destinée au dépôt et à la diffusion de documents scientifiques de niveau recherche, publiés ou non, émanant des établissements d'enseignement et de recherche français ou étrangers, des laboratoires publics ou privés. 


\title{
THz-bandwidth coherence measurements of a quantum dash laser in passive and active mode-locking operation
}

\author{
Eamonn Martin, ${ }^{1}$ Regan Watts, ${ }^{1, *}$ Laurent Bramerie, ${ }^{2}$ Alexandre Shen, ${ }^{3}$ Harry Gariah,${ }^{3}$ Fabrice \\ Blache, ${ }^{3}$ François Lelarge,${ }^{3}$ and Liam Barry ${ }^{1}$ \\ ${ }^{1}$ The Rince Institute, Dublin City University, Glasnevin, Dublin 9, Ireland \\ 2 Université Européenne de Bretagne (UEB), CNRS-Foton Laboratory (UMR 6082) / \\ Universit de Rennes 1, Enssat, BP 80518, 22305 Lannion Cedex, France \\ ${ }^{3}$ III-V Lab, a joint laboratory of "Alcatel Lucent Bell Labs" and "Thales Research 8 Technology" and \\ CEA-LETI, 91460 Marcoussis, France \\ *Corresponding author: regan.watts@dcu.ie
}

Compiled July 12, 2012

\begin{abstract}
This research carries out coherence measurements of a $42.7 \mathrm{GHz}$ quantum dash (QDash) semiconductor laser when passively, electrically and optically mode-locked. Coherence of the spectral lines from the mode-locked laser is determined by examining the radio frequency $(\mathrm{RF})$ beat-tone linewidth as the mode spacing is increased up to 1.1THz. Electric field measurement of the QDash laser are also presented, from which a comparison between experimental results and accepted theory for coherence in passively mode-locked lasers has been performed. (C) 2012 Optical Society of America

OCIS codes: (140.5960) Semiconductor lasers; (190.4380) Non-linear optics, four-wave mixing
\end{abstract}

The use of THz-band radiation for imaging and spectroscopic applications has been contemporarily designated by the technical and research community to cover the electro-magnetic frequency band between 300GHz$3 \mathrm{THz}$. The emergence of high power, coherent $\mathrm{THz}$ radiation sources has, among other applications, enabled molecular spectroscopic interrogation of a frequency band which contains several biochemically-important spectral components, including hydroxide, methanol and water [1].

Two popular approaches of generating $\mathrm{THz}$ radiation include frequency up-conversion from microwave frequencies $(20-40 \mathrm{GHz})$ and frequency down-conversion from infra-red frequencies $(\sim 200 \mathrm{THz})$. Both techniques can generate continuous wave $(\mathrm{CW}) \mathrm{THz}$ radiation with linewidths between $10 \mathrm{kHz}$ and $10 \mathrm{MHz}$, enabling them to be used in atmospheric gas spectroscopy applications [2]. Frequency up-conversion is a mature technology in which microwave sources are harmonically mixed up to the $\mathrm{THz}$ band, though it suffers from mixing inefficiency and high power consumption [3]. Frequency down-convertors typically use lasers with multi- $\mathrm{THz}$ spectral coverage which are converted down to lower $\mathrm{THz}$ frequencies using GaAs photomixers or electro-optic crystals. Quantum cascade lasers (QCL) are commonly used as $\mathrm{THz}$ sources as they demonstrate high output powers and can operate freerunning with spectral linewidths around tens of $\mathrm{kHz}$ [4], or can be injected electrically or optically to achieve $\mathrm{Hz}$ linewidths $[5,6]$. However, a key drawback of QCLs is they require cryogenic cooling to achieve prolonged high power outputs. There is an ongoing interest in emerging laser sources for $\mathrm{THz}$ spectroscopy where important considerations include device power consumption in relation to optical output power, device size and spectral purity. In this letter, the use of a quantum dash (QDash) semiconductor laser as an optical laser source for $\mathrm{THz}$ generation through frequency down conversion is promoted. QDash semiconductor mode-locked lasers are a promising technology fit owing to their low power requirements, mm-scale device footprint and monolithic manufacturability [7]. With a spectral full-width half maximum (FWHM) of $1.6 \mathrm{THz}$, passively mode-locked QDash lasers have previously been shown to have an RF beat-tone of $\sim 10 \mathrm{MHz}$ at a $1 \mathrm{THz}$ spectral mode separation [8]. Here, THz beat-tone coherence measurements of a QDash laser when passively mode-locked and injection mode-locked using both electronic and optical master signals are demonstrated.

The device used in this research is a $42.7 \mathrm{GHz}$ quantum dash Fabry-Perot mode locked laser, fabricated at III-V Labs. The structure of this laser has been detailed in a previous publication [9]. A temperature probe, a Peltier cooler, and a microwave V-type connector have been integrated with the QDash semiconductor laser into a butterfly module. Throughout this research the QDash laser was driven by a DC bias current of $100 \mathrm{~mA}$ and held at a constant temperature of $26^{\circ} \mathrm{C}$. Fig. 1 demonstrates the three laser setups used. Fig. 1(a) illustrates the passively mode-locked QDash laser setup. Fig. 1(b) depicts the setup for the electrically mode-locked QDash laser where $4 \mathrm{dBm}$ of electrical power from a $42.7 \mathrm{GHz} \mathrm{RF}$ synthesizer was used to actively lock the laser. Fig. 1(c) shows the mode-locking of the QDash laser through optical injection. Around $1 \mathrm{dBm}$ of optical power is injected inside the cavity of the QDash module through an optical circulator. The optical signal is generated using an external cavity laser (ECL) modulated by a Mach-Zehnder modulator (MZM) and a $42.7 \mathrm{GHz}$ RF synthesizer. Fig. 1(d) shows the optical spectrum generated by the passively mode-locked laser at a DC bias current of $100 \mathrm{~mA}$. 
(a)

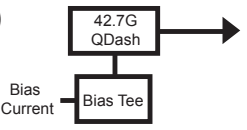

(c)

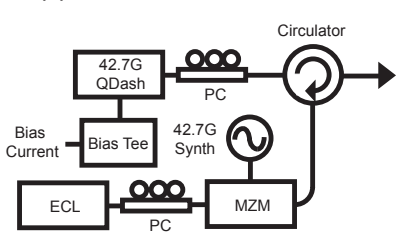

(b)

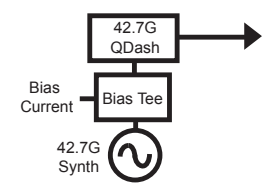

(d)

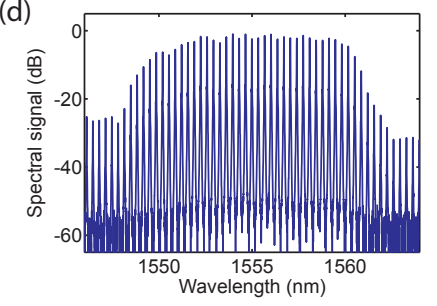

Fig. 1. (Color online) Quantum dash semiconductor (QDash) laser setup: (a) passively mode locked, (b) electrically mode-locked using a $42.7 \mathrm{GHz} \mathrm{RF}$ synthesizer, (c) mode-locked by optical injection, using an ECL modulated with an MZM and $42.7 \mathrm{GHz}$ RF synthesizer, and (d) optical spectrum of the passively mode locked laser.

The electric field of the QDash laser was measured for the three distinct methods of mode-locking using the stepped heterodyne measurement technique outlined in [10]. The spectral field and temporal field of similar QDash lasers have been presented in prior literature $[7,10]$, and the device used in this study displayed the characteristic square spectral intensity profile with a bandwidth of $\sim 1.6 \mathrm{THz}$ and possesses a large group delay dispersion of $\sim 2 \mathrm{ps}^{2}$ for all three mode-locking mechanisms. The dispersion profile was characterised using the stepped heterodyne measurements and compensated for using a programmable optical filter (Finisar WaveShaper 1000S). The transform-limited pulse duration, $\tau$, for the passively, electrically and optically-injected mode-locked QDash laser was 637fs, 636fs and 611fs, respectively.

A comparison between two ultrafast measurement techniques of the stepped heterodyne and an optical sampling oscilloscope (OSO, an EXFO PSO100) under identical launch conditions is demonstrated. Here, the QDash laser is mode-locked using optical injection, the signal is then amplified using an erbium-doped fiber amplifier (EDFA) to boost the signal for the OSO. Fig. 2 shows the temporal intensity measured by the OSO (red dots) and the stepped heterodyne technique (solid blue line) for the pulsation coming from the QDash laser with ideal dispersion compensation. The inset to Fig. 2 illustrates the detail in the measured pulses. The OSO measures a pulse width of $960 \mathrm{fs}$ while the stepped heterodyne measures a more complex pulse shape with a pulse width of $645 \mathrm{fs}$. The $1 \mathrm{THz}$ measurement bandwidth of the OSO is insufficient to measure the ultra-fast structure of the compensated pulses from the QDash laser.

To measure the RF linewidth of two adjacent modes a $80 \mathrm{GHz}$-bandwidth bandpass filter, created by the programmable optical filter, was used to filter off two adjacent modes separated by $42.7 \mathrm{GHz}$. Subsequently, the $\mathrm{RF}$ beat-tone linewidth of these two modes was meas-

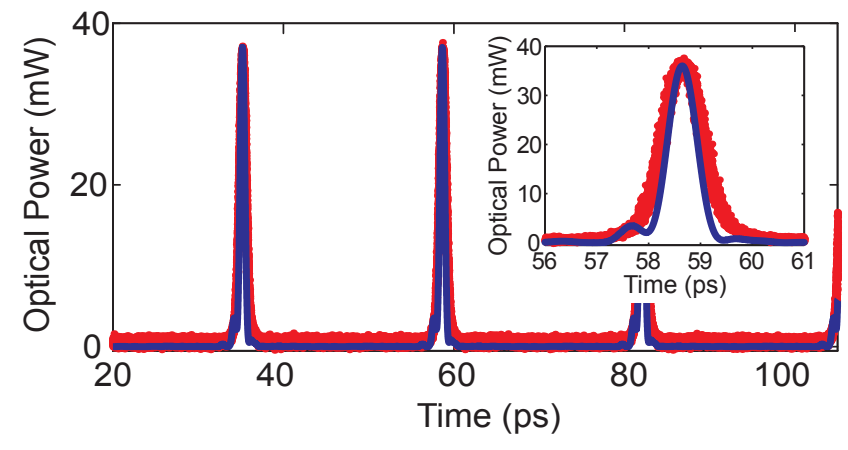

Fig. 2. (Color online) Pulses from the QDash laser as measured by OSO (red dots) and stepped heterodyne (solid blue line) with ideal dispersion compensation. Inset reveals detail in the temporal distribution.

ured using a fast photodiode and an electrical spectrum analyzer (ESA). This process was carried out across the entire spectrum when the QDash laser was passively, electrically and optically mode-locked using the setups illustrated in Fig. 1. The passively mode-locked QDash laser gives an RF linewidth of approximately $7 \mathrm{kHz}$. A value of $30 \mathrm{~Hz}$ was measured for the $\mathrm{RF}$ linewidth of adjacent modes of the actively mode-locked QDash laser for both the electrically and optically injected setups. The low value for RF linewidth is attributed to the low phase-noise of the $42.7 \mathrm{GHz}$ RF synthesizer used in the actively mode-locked QDash laser setups.

As the RF beat-tone for the non-adjacent modes is too high in frequency to use conventional electrical domain measurement techniques, a method which utilizes optical down-conversion is employed. The setup for this measurement technique is demonstrated in Fig. 3. Initially, a set of non-adjacent modes are filtered off corresponding to a mode separation greater than $42.7 \mathrm{GHz}$. The two modes at these particular frequency spacings are down converted by a degenerate four wave mixing (FWM) wavelength conversion technique to frequency spacings with a mode separation of less than 10GHz. Subsequently, the RF beat-tone linewidth of the two modes can be measured using a $10 \mathrm{GHz}$ photodiode, an $\mathrm{RF}$ amplifier and a 10GHz-bandwidth real-time scope [8]. The experiment was carried out for the passively and both actively mode-locked QDash laser setups shown in Fig. 1 for non-adjacent modes out to the 26th harmonic, corresponding to a mode separation of $1.1 \mathrm{THz}$.

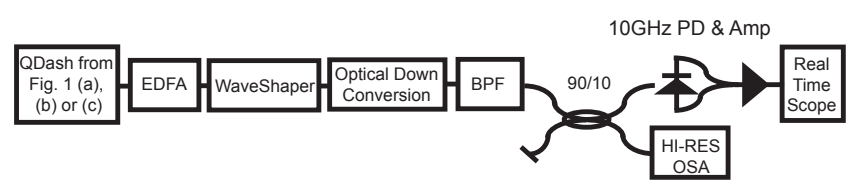

Fig. 3. Experimental setup to measure RF linewidth of non-adjacent modes utilising suitable filtering, an optical down-conversion technique, a $10 \mathrm{GHz}$ photodiode, an amplifier and a real-time scope. 
The RF beat-tone measurements are conveyed in Fig. 4 as a function of the spectral mode separation. The red circles specify the measured RF beat-tone linewidths of the QDash laser for the passive case and follows a trend in agreement with measurements performed on a similar device [8]. A quadratic trend is fitted to measured data, indicated by the solid red line, following theory outlined in [11]. The RF linewidth, $\Delta \omega_{R F_{m}}$, of the $m^{t h}$ frequency harmonic of a mode-locked laser is described by,

$$
\Delta \omega_{R F_{m}}=\frac{4 \pi^{2}}{M^{2}} \Delta \omega_{t} m^{2}
$$

where, $M=\frac{T}{\tau}$ is the ratio of the pulse repetition period, $T$, and the transform-limited pulse width, $\tau$. For the passively mode-locked QDash laser, $\mathrm{M}=37 \mathrm{spec}-$ tral modes. $\frac{\Delta \omega_{t}}{(2 \pi)}$ is the microwave linewidth factor and is found by regressively fitting the theory to the data to be $285.7 \mathrm{kHz}$. The regressed fit is shown in Fig. 4 as the solid red line. The theory predicts the RF linewidth of the first harmonic (adjacent spectral modes) to be $\frac{\Delta \omega_{R F_{1}}}{(2 \pi)}=8.3 \mathrm{kHz}$, in good agreement with what is measured using an ESA $(7 \mathrm{kHz})$. The fit also found an RF linewidth offset of $330.2 \mathrm{kHz}$, in agreement with the measured linewidth resolution limitation of $\sim 330 \mathrm{kHz}$ imposed by the FWM-based wavelength convertor, as described in detail in [8]. The measured RF beat-tone linewidths of the QDash laser for the electrically and optically injected mode-locked QDash laser setups are represented by blue diamonds and green squares, respectively. For both the electrically and optically mode-locked cases the $\mathrm{RF}$ beat-tone linewidths remains constant out to spectral mode separations out to $1.1 \mathrm{THz}$ implying the coherence of widely-spaced spectral modes is signficantly better than that of the passively mode-locked laser. Theory predicts that the actively mode-locked lasers should also demonstrate a quadratically-increasing RF beattone linewidth with increasing mode separation, however the slope of the quadratic will be dependent on the laser structure and mode-locking mechanism (or the magnitude of the microwave linewidth factor). In this case, the microwave linewidth factor for the actively modelocked QDash lasers will be much smaller than passively mode-locked laser, and the quadratic dependence of the $\mathrm{RF}$ beat-tones can not be observed due to the frequency resolution limitation imposed by the optical wavelength conversion technique.

In conclusion, the evolution of the spectral mode coherence of a passively and actively mode-locked QDash laser over $1 \mathrm{THz}$ spectral bandwidth has been investigated. The RF linewidth of the passively mode-locked laser followed a quadratic evolution with respect to increasing spectral mode separation in good agreement with theory. The actively mode-locked schemes revealed consistently low RF linewidths out to the 26th frequency harmonic, or $1110.2 \mathrm{GHz}$. In addition to this, field measurements were made for all three mode-locking

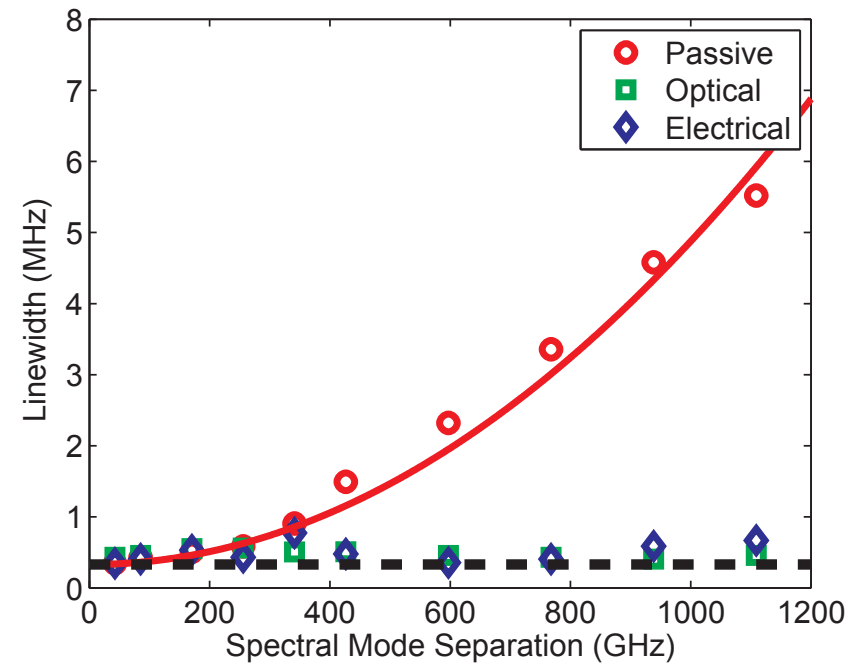

Fig. 4. (Color online) Measured RF beat-tone linewidth (red circles) for two spectral modes as a function of increasing spectral mode separation. Passive mode-locking is shown with red circles (solid red line shows theoretical fit). Active mode-locking with an electrical frequency source (blue diamonds) and optical injection (green squares) are also shown. The dashed black line depicts the minimum $\mathrm{RF}$ linewidth resolvable with the measurement technique $(330 \mathrm{kHz})$.

schemes yielding sub-picosecond pulses after dispersion compensation.

This work was supported by the PRTLI Cycle 5. The PRTLI is co-funded through the European Regional Development Fund (ERDF), part of the European Union Structural Funds Programme 2007-2013. This work was also supported by Science Foundation Ireland through the Principle Investigator programme and the International Centre for Graduate Education in Micro \& Nano Engineering (ICGEE), and by Region Bretagne and the French National projects TELDOT and PERSYST II.

\section{References}

1. B. J. Drouin, F. W. Maiwald, and J. C. Pearson, Review of Scientific Instruments 76, 093113 (2005).

2. P. Siegel, Microwave Theory and Techniques, IEEE Transactions on 50, 910 (2002).

3. G. Chattopadhyay, E. Schlecht, J. Ward, J. Gill, H. Javadi, F. Maiwald, and I. Mehdi, Microwave Theory and Techniques, IEEE Transactions on 52, 1538 (2004).

4. A. Barkan, F. K. Tittel, D. M. Mittleman, R. Dengler, P. H. Siegel, G. Scalari, L. Ajili, J. Faist, H. E. Beere, E. H. Linfield, A. G. Davies*, and D. A. Ritchie, Opt. Lett.29, 575 (2004).

5. P. Gellie, J.-F. Lampin, C. Sirtori, and S. Barbieri, Electronics Letters 46, s60 (2010).

6. M. Ravaro, C. Manquest, C. Sirtori, S. Barbieri, G. Santarelli, K. Blary, J.-F. Lampin, S. P. Khanna, and E. H. Linfield, Opt. Lett. 36, 3969 (2011).

7. R. Rosales, S. G. Murdoch, R. Watts, K. Merghem, A. Martinez, F. Lelarge, A. Accard, L. P. Barry, and A. 
Ramdane, Opt. Express 20, 8649 (2012).

8. R. Watts, R. Rosales, F. LeLarge, A. Ramdane, and L. Barry, Opt. Lett. 37, 1499 (2012).

9. G. Girault, M. Gay, S. Lobo, L. Bramerie, M. Joindot, J. Simon, A. Shen, F. Blache, H. Gariah, F. Mallecot, O. Le Gouezigou, F. Poingt, L. Le Gouezigou, F. Pommereau, B. Rousseau, F. Lelarge, and G.-H. Duan, Electronics Letters 44, 873 (2008).

10. S. G. Murdoch, R. T. Watts, Y. Q. Xu, R. MaldonadoBasilio, J. Parra-Cetina, S. Latkowski, P. Landais, and L. P. Barry, Opt. Express 19, 13628 (2011).

11. F. Kärtner," Few-Cycle Laser Pulse Generation And Its Applications", Topics in Applied Physics (Springer, 2004).

\section{Informational Fourth Page}

\section{References}

1. B. J. Drouin, F. W. Maiwald, and J. C. Pearson, "Application of cascaded frequency multiplication to molecular spectroscopy," Review of Scientic Instruments $\mathbf{7 6}$, 093113 (2005).

2. P. Siegel, "Terahertz technology," Microwave Theory and Techniques, IEEE Transactions on 50, 910 -928 (2002).

3. G. Chattopadhyay, E. Schlecht, J. Ward, J. Gill, H. Javadi, F. Maiwald, and I. Mehdi, "An all-solid-state broad-band frequency multiplier chain at 1500 ghz," Microwave Theory and Techniques, IEEE Transactions on 52, 1538 - 1547 (2004).

4. A. Barkan, F. K. Tittel, D. M. Mittleman, R. Dengler, P. H. Siegel, G. Scalari, L. Ajili, J. Faist, H. E. Beere, E. H. Linfield, A. G. Davies*, and D. A. Ritchie, "Linewidth and tuning characteristics of terahertz quantum cascade lasers," Opt. Lett. 29, 575-577 (2004).

5. P. Gellie, J.-F. Lampin, C. Sirtori, and S. Barbieri, "Rf injection-locking of terahertz quantum cascade lasers," Electronics Letters 46, -s60 -s64 (2010).

6. M. Ravaro, C. Manquest, C. Sirtori, S. Barbieri, G. Santarelli, K. Blary, J.-F. Lampin, S. P. Khanna, and E. H. Linfield, "Phase-locking of a 2.5thz quantum cascade laser to a frequency comb using a gaas photomixer," Opt. Lett. 36, 3969-3971 (2011).

7. R. Rosales, S. G. Murdoch, R. Watts, K. Merghem, A. Martinez, F. Lelarge, A. Accard, L. P. Barry, and A. Ramdane, "High performance mode locking characteristics of single section quantum dash lasers," Opt. Express 20, 8649-8657 (2012).

8. R. Watts, R. Rosales, F. LeLarge, A. Ramdane, and L. Barry, "Mode coherence measurements across a $1.5 \mathrm{THz}$ spectral bandwidth of a passively mode-locked quantum dash laser," Optics Letters 37, 1499-1501 (2012)

9. G. Girault, M. Gay, S. Lobo, L. Bramerie, M. Joindot, J. Simon, A. Shen, F. Blache, H. Gariah, F. Mallecot, O. Le Gouezigou, F. Poingt, L. Le Gouezigou, F. Pommereau, B. Rousseau, F. Lelarge, and G.-H. Duan, "Quantum dash actively modelocked fabry-perot laser module demonstrated as part of wavelength tunable rz transmitter," Electronics Letters 44, 873 -874 (2008).

10. S. G. Murdoch, R. T. Watts, Y. Q. Xu, R. MaldonadoBasilio, J. Parra-Cetina, S. Latkowski, P. Landais, and L. P. Barry, "Spectral amplitude and phase measurement of a $40 \mathrm{Ghz}$ free-running quantum-dash modelocked laser diode," Opt. Express 19, 13628-13635 (2011).

11. F. Kärtner, Few-Cycle Laser Pulse Generation And Its Applications, Topics in Applied Physics (Springer, 2004). 